\title{
As relações interpessoais nas ações de cuidar em ambiente tecnológico hospitalar*
}

\author{
The interpersonal relationships of care actions in the hospital technological environment \\ Las relaciones interpersonales en las acciones de cuidar en un ambiente tecnológico hospitalario
}

\author{
Patrícia Julimeire Cunha ${ }^{1}$, Ivete Palmira Sanson Zagonel $^{2}$
}

\begin{abstract}
RESUMO
Objetivo: Compreender como se estabelecem as relações interpessoais nas ações de cuidado à criança em ambiente tecnológico hospitalar. Métodos: A metodologia é qualitativa, o método é fenomenológico e o referencial teórico de Paterson e Zderad. Foram entrevistados 10 profissionais da equipe de saúde. Resultados: Da análise fenomenológica resultaram 11 unidades de significado e 4 categorias convergentes: Compreendendo a atitude humanística como mobilizadora das relações interpessoais em ambiente tecnológico hospitalar; as relações interpessoais no ambiente tecnológico hospitalar envolvendo a equipe de saúde; o sentido da presença da família nas relações interpessoais com a equipe de saúde; a dinamicidade do cuidado permeando a conduta a ser tomada em ambiente tecnológico hospitalar. Conclusão: A aplicabilidade de conceitos humanísticos em ambientes complexos e de grande aparato tecnológico como a Unidade de Terapia Intensiva Pediátrica Cardíaca modifica seres e fazeres com vistas à construção de vínculos afetivos e de responsabilização sobre as ações das práticas de saúde.
\end{abstract}

Descritores: Cuidados de enfermagem; Relações Interpessoais; Enfermagem pediátrica

\begin{abstract}
Objective: To understand how interpersonal relationships are established in the care actions to children in the hospital technological environment. Methods: The methodology is quantitative, the method is phenomenological and the theoretical framework is that of Paterson \& Zderad. Interviews were carried out with ten health team professionals. Results: The phenomenological analyses resulted in 11 meaning units and four converging categories: understanding that humanistic attitude mobilizes interpersonal relationships in the hospital technological environment; the interpersonal relationships in the hospital technological environment involving the health team; the meaning of the family's presence in the interpersonal relationships with the health team; the dynamicity of care permeating the conduct that should be followed in a hospital technological environment. Conclusion: The applicability of humanistic concepts in complex environments with a large technological apparatus, such a the Cardiac Pediatric Intensive Care Unit changes beings and actions with a view to build affective and responsibility attachments over health practice actions.
\end{abstract}

Keywords: Nursing care; Interpersonal relations; Pediatric nursing

\section{RESUMEN}

Objetivo: Comprender cómo se establecen las relaciones interpersonales en las acciones de cuidado al niño en un ambiente tecnológico hospitalario. Métodos: La metodología es cualitativa, el método fenomenológico siendo el referencial teórico el de Paterson y Zderad. Fueron entrevistados 10 profesionales del equipo de salud. Resultados: Del análisis fenomenológico resultaron 11 unidades de significado y 4 categorías convergentes: Comprendiendo la actitud humanística como movilizadora de las relaciones interpersonales en un ambiente tecnológico hospitalario; las relaciones interpersonales en un ambiente tecnológico hospitalario que involucra al equipo de salud; el sentido de la presencia de la familia en las relaciones interpersonales con el equipo de salud; el dinamismo del cuidado que permea la conducta a ser tomada en un ambiente tecnológico hospitalario. Conclusión: La aplicabilidad de los conceptos humanísticos en ambientes complejos y de gran aparato tecnológico como es la Unidad de Terapia Intensiva Pediátrica Cardiaca, modifica el ser y hacer con vistas a la construcción de vínculos afectivos y de responsabilidad sobre las acciones de las prácticas de salud.

Descriptores: Cuidado de enfermería; Relaciones interpersonales; Enfermería pediátrica

\footnotetext{
* Artigo extraído da Dissertação de Mestrado do Programa de Pós-Graduação em Enfermagem da Universidade Federal do Paraná - UFPR - Curtiba (PR), Brasil; defendida em 11 de fevereiro de 2007.

1 Mestre, Professora do Curso de Enfermagem da Faculdade Pequeno Prínicipe - FPP - Curtiba (PR), Brasil;

2 Doutora, Professora do Programa de Pós-Graduação em Saúde da Criança e do Adolescente da Faculdade Pequeno Prínicipe - FPP - Curtiba (PR), Brasil.
} 


\section{INTRODUÇÃO}

Nas relações interpessoais que se estabelecem na prática cotidiana do cuidar em ambiente tecnológico hospitalar, fica evidente que para efetivar a compreensão do paciente e das pessoas que convivem mutuamente são necessárias a escuta, a presença e a sensibilidade para ativar a verdadeira dimensão das características existenciais de cada partícipe dessa relação. A expressão ambiente tecnológico hospitalar designa a Unidade de Terapia Intensiva Pediátrica Cardíaca (UTIP Cardíaca), contexto desse estudo, ambiente de constantes relações profissionais e, portanto, interpessoais.

As relações intersubjetivas que se estabelecem entre os profissionais de saúde manifestam-se de forma única, de acordo com o referencial de vida de cada membro da equipe, e destes com os clientes. Nos relacionamentos, cada um coloca um pouco de si, mostra seu modo de agir e influencia o outro de forma positiva ou negativa. Auxiliar a pessoa a reorganizar sua existência ao passar pela experiência da doença, é papel da equipe de saúde, por meio da percepção, presença, compromisso, solidariedade e, principalmente, de interações humanas.

Tornar o ambiente tecnológico hospitalar da UTIP Cardíaca em ambiente de interação, humanização, trocas intersubjetivas e de relação dialógica pressupõe ultrapassar barreiras, abrir caminhos que possam direcionar as mudanças necessárias para a prática do cuidado solidário e resultar em ações benéficas e eficazes à criança, sua família e equipe. Somente com a interação das duas dimensões cuidativas, a tecnológica e a humana é possível prestar o cuidado solidário, individual e qualificado à criança hospitalizada em UTIP Cardíaca, família e equipe de saúde, ao compatibilizar o conhecimento técnicocientífico com a intuição, valorização da afetividade e respeito ao ser humano ${ }^{(1)}$.

Para alcançar as respostas, este artigo trata da investigação realizada pelas autoras, a qual foi direcionada às pessoas envolvidas nesse processo de cuidar, considerando que o ser humano constrói o próprio processo vital fundamentado em suas vivências e diferentes formas de compreender e relacionar-se ${ }^{(2)}$.

Incluímos nesse contexto de cuidado à criança, como sujeitos da pesquisa, a equipe de saúde, por considerarmos essencial compreender como se estabelecem as relações interpessoais nas ações de cuidar em ambiente tecnológico hospitalar.

A atuação da primeira autora no contexto de UTIP Cardíaca, a partir de sua experiência de cuidado, possibilitou perceber a situação vivenciada pela criança, família e equipe de saúde durante a hospitalização, e que as pessoas envolvidas necessitavam ativar uma forma diferenciada de cuidar, em que a intersubjetividade fosse a norteadora, enfocando o ser humano como princípio de toda ação. Durante a experiência singular de cuidar das crianças na UTIP Cardíaca percebeu que o caráter relacional do cuidado tinha implicações com a intersubjetividade que se estabelece na relação interpessoal.

É incontestável o papel relevante dos recursos tecnológicos para o sucesso do tratamento e suporte parcial ou total da vida da criança criticamente enferma. No entanto, deve ser perpetuada a subordinação da tecnologia ao homem, e não a subordinação do homem à tecnologia. Ninguém questiona a importância da existência da tecnologia, porque ela em si não é benéfica nem maléfica, tudo depende do uso que se faz dela. E também não se pode impedir que ela exista, nem ignorá-la, isto seria um retrocesso do desenvolvimento( ${ }^{(3)}$. Os equipamentos têm seu valor, desde que resguardados os princípios técnicos e humanos indispensáveis, tanto no diagnóstico como no tratamento, na manutenção e, sobretudo, na valorização da vida. A tecnologia é imprescindível, mas deve ser questionada quanto à utilização e o sentido do seu uso ${ }^{(4)}$.

A subjetividade refere-se à capacidade que o ser humano tem de ser singular. Antes de ser comunidade, o ser humano é pessoal, particular, reservado, privado. Não é possível ser somente na solidão, o singular é tocado o tempo todo por outro singular e assim nascem os encontros, e desses temos a relação intersubjetiva. Toda relação é um encontro de subjetividades ${ }^{(5)}$.

A intersubjetividade se manifesta "como história relacional vivida, como linguagens, intercomunicação, conhecimento, valores, crenças, emoções, desejos, temores, perspectivas, projetos"(6). Para compreender a realidade, na qual estamos envolvidos é preciso mergulhar na subjetividade e em sua essência, sem desconsiderar a objetividade que a permeia.

A dissociação, o distanciamento entre a tecnologia e humanização está presente na UTIP desde seu surgimento na década de 60 , em que, a partir desse período, o rápido desenvolvimento tecnológico, aspecto que atualmente possibilita uma qualidade na assistência à criança criticamente enferma, sobrepõe-se à dimensão humana de cuidar. Dessa forma, nesse ambiente as atenções, de forma geral, estão voltadas à tecnologia, priorizando o funcionamento do aparelho em detrimento do ser humano.

Cada vez que o sujeito é desconsiderado como organismo vivo, colocado na condição de mecanismo de objeto manuseável, este, perde sua subjetividade. ${ }^{(5)}$

Cuidar do ser humano exige uma reflexão aprofundada por parte dos profissionais de saúde, os quais devem perceber que a continuidade da dissociação entre priorizar a tecnologia às ações humanas, já não consegue prosseguir, pois é imperativo o uso simultâneo destas vertentes do cuidar.

Para encontrar eco às inquietações colocadas, optamos pelo referencial teórico de Paterson e Zderad, 
considerando-se pertinente e adequado para conduzir este trabalho. Para as autoras, a relação dialógica é a categoria existencial por excelência, pois ajuda na compreensão da realidade por meio da experiência vivida (ação), da reflexão (pensamento) e do relacionamento, permite abertura para que os seres humanos experienciem o mundo e a si próprios de forma integral. A relação dialógica é uma forma de diálogo que implica uma esfera ontológica, uma forma particular de relação intersubjetiva mediante a qual é possível ver o outro como ser distinto e único, em mútua relação ${ }^{(7)}$.

A opção pela teoria humanista de Paterson e Zderad ocorreu porque contempla a prática da enfermagem humanística, o fenômeno da enfermagem como bemestar, potencial humano, a transação intersubjetiva, o diálogo vivo desenvolvido pelo encontro, relação, a presença e o fenômeno da comunhão ${ }^{(8)}$. Na prática, a teoria humanística depende da experiência, concepção, participação e do ponto de vista particular de cada enfermeiro em relação às suas vivências no mundo e na enfermagem.

A aplicabilidade das idéias teóricas de Paterson e Zderad em ambiente tecnológico hospitalar nos fez refletir e delinear o conceito de cuidado, o qual emerge de leituras e vivências

O cuidado sob nossa visão envolve uma atitude relacionada a sentimento de um ser humano para com outro ser humano, para com algo que, fundamentado num processo interativo, é realizado respeitando a dimensão existencial do ser e valorizando a expressão da experiência de vida de ambos, no momento do cuidar. $O$ cuidado ocorre nessa intersubjetividade humana, em uma relação dialógica de encontro genuíno entre profissional e ser cuidado, em um movimento de complementaridade de sentimentos, ações e reações. O cuidado se realiza de forma humana, calorosa e atenciosa, em que as percepções dos profissionais associam-se a emoções e, conseqüentemente, podem resultar em melhora no estado do doente.

Nesse sentido, "a intersubjetividade viva do momento assistencial permite escapar a uma objetivação 'desubjetivadora' exatamente porque ali se efetiva uma troca, um espaço relacional, que extrapola o tecnológico. Apóia-se na tecnologia, mas não se subordina a ela, subverte-a". A sabedoria prática não cria objetos, mas realiza sujeitos diante dos objetos criados no e para seu mundo $^{(9)}$.

Entendemos que o objetivo do estudo, de compreender como se estabelecem as relações interpessoais nas ações de cuidar em ambiente tecnológico hospitalar, demonstra que o cuidado à criança, necessita de atenção especial, para que o profissional possa cuidar por inteiro na relação com o outro, mobilizando a própria experiência, conhecimento e referenciais de vida, para ultrapassar a rigidez da técnica e aderir ao modelo sensível e dialógico de cuidar.

\section{MÉTODOS}

Para desenvolver este estudo, escolhemos a metodologia qualitativa por meio do método fenomenológico. As experiências vividas de cada sujeito envolvido ofereceram significado à percepção da equipe de saúde sobre o fenômeno particular das relações interpessoais no ambiente tecnológico hospitalar, e coube ao método fenomenológico auxiliar na captação dessa experiência vivida, bem como as compreensões e interpretações que cada ser percebeu.

O local da vivência do fenômeno foi um hospital infantil de grande porte de Curitiba, na UTIP Cardíaca. Esta unidade atende crianças e adolescentes de ambos os sexos, de 0 a 18 anos, que necessitam de cuidados complexos e controles precisos. São admitidos após cirurgia cardíaca, cateterismo cardíaco, exame eletrofisiológico ou situações clínicas cardíacas que necessitem de cuidados intensivos.

Os princípios da bioética foram considerados na realização da pesquisa por ser esse o caminho que garante aos sujeitos a preservação da dignidade dos seres humanos (10). Antes de iniciar as entrevistas, o projeto foi submetido ao Comitê de Ética da instituição envolvida, do qual recebeu o protocolo de n. ${ }^{\circ}$ 295/06 de sua aprovação. Todos os sujeitos assinaram o Termo de Consentimento Livre e Esclarecido.

Foram entrevistados dez sujeitos, componentes da equipe de saúde da UTIP Cardíaca, incluindo enfermeiros, médicos, técnicos e auxiliares de enfermagem. Para a seleção deveriam atuar no cuidado à criança e ter disponibilidade para participar. O tamanho da amostra considerou a saturação das informações.

Para a coleta dos depoimentos, utilizamos a entrevista semi-estruturada por combinar perguntas estruturadas e não estruturadas, permitindo flexibilidade e facilidade nas expressões. A expressividade é de intensa importância no método fenomenológico para que se possa apreender a realidade vivida.

Para efetivar a entrevista fenomenológica com os membros da equipe de saúde, utilizamos, como forma sistematizadora, quatro das etapas do processo de enfermagem propostas por Paterson e Zderad, pois entendemos que é possível fazer essa analogia, uma vez que as etapas são similares e representam o momento de encontro para a apreensão de informações ${ }^{(7)}$. O contato com os sujeitos, o próprio encontro para iniciar a pesquisa, já é um diálogo fenomenológico, pois cada sujeito expressa sua forma de ser e pensar, sua visão de mundo, seu modo de ser, momento em que o pesquisador e ser pesquisado unem interesses para melhor captar as 
significações existenciais experienciadas.

Para responder à questão norteadora "Como se estabelecem as relações interpessoais nas ações de cuidar em ambiente tecnológico hospitalar", formulamos as seguintes perguntas à equipe de saúde: o que significa para você o cuidado no ambiente tecnológico hospitalar em que atua; você considera que é possível incorporar no processo de cuidar a atitude humanística; e quais as exigências para essa incorporação. As etapas da entrevista seguiram os passos do processo de cuidar de Paterson e Zderad, com adaptações das pesquisadoras, para adequarse ao estudo.

Preparando-me para conhecer os membros da equipe - nesta fase levamos em consideração durante a entrevista, o que Paterson e Zderad enfatizam. O enfermeiro prepara a mente para conhecer o campo da prática ou o campo da pesquisa com leituras de literaturas que levem à reflexão sobre a prática da enfermagem e que estimulem a reflexão crítica do enfermeiro sobre a percepção que o ser humano tem de si mesmo e de suas relações com o mundo. Neste momento, inicia o autoconhecimento. $\mathrm{O}$ caráter transacional intersubjetivo da equipe de saúde não pode passar despercebido quando se vive o fenômeno, e durante a realização da entrevista ocorreu essa transação de conhecimento dos membros da equipe de saúde, como um evento inter-humano.

Conhecendo intuitivamente os membros da equipe: a relação eu-tu - para a realização das entrevistas, contatamos pessoalmente cada um dos entrevistados e efetivamos o convite para participar do estudo, quando foram esclarecidos os motivos da pesquisa e agendados os horários. Os locais escolhidos foram, na grande maioria, ambientes externos ao da UTIP Cardíaca. Para Paterson e Zderad cada encontro indivíduo-enfermeira-equipe difere, pois cada participante se apresenta como um indivíduo singular que é, com suas próprias expectativas e capacidades, para dar e receber ajuda. Identificamos cada profissional entrevistado de acordo com a potencialidade humana mais intensamente revelada, sua singularidade durante os relatos, caracterizando a relação eu-tu.

Conhecendo cientificamente o outro: eu - isso fora do local de estudo, o pesquisador resignifica, reflete o apreendido e transcreve seu ponto de vista particular. Os relatos revelaram o modo de ser e agir da equipe de saúde em relação ao mundo de coisas que os cercam no ambiente tecnológico hospitalar, conformando a relação eu-isso. Essa fase é particular ao pesquisador, pois conhece cientificamente o outro, infere sobre o que foi dito, e delineia as primeiras impressões, cientificamente, em linguagem de pesquisador.
Sintetizando de forma complementar as realidades conhecidas - a partir das entrevistas com a equipe de saúde em ambiente tecnológico hospitalar, refletimos sobre o conhecimento intuitivo e o conhecimento científico adquirido pelas expressões dos vários diálogos vividos, para então iniciar a conexão do eu-tu, do eu-isso e conformar o eu-nós. Essa fase exige profunda reflexão para alcançar a síntese da realidade conhecida.

Concluída a coleta das informações iniciamos a análise, a qual seguiu a técnica de análise fenomenológica, que tem por objetivo a busca da essência do fenômeno por meio da descrição do "sujeito situado" e os significados emergidos do diálogo vivido tornam-se o conteúdo de análise. A técnica proposta para a análise percorreu quatro passos essenciais do método fenomenológico ${ }^{(11)}$ : Apreender o significado dentro da estrutura global, por meio da leitura atenta do conteúdo total, expresso de forma a identificar atributos ou elementos presentes; Identificar as unidades de significado dentro da perspectiva do pesquisador por meio da releitura do texto transformando as expressões do sujeito em linguagem de pesquisador, para discriminar afirmações significativas; Refletir intuitivamente para expressar aquilo que é significativo nas unidades, tendo a questão norteadora como orientação; Sintetizar todas as unidades pela análise compreensiva das descrições.

As unidades de significado emergiram como conseqüência do processo de análise, como discriminações espontaneamente percebidas dentro da descrição do sujeito, tendo o pesquisador a postura de atitude adequada, tematizando o objetivo a ser alcançado na pesquisa. As unidades de significado foram numeradas, assinaladas, destacadas no texto durante a realização da leitura. Para alcançar essa etapa foram necessárias leituras cuidadosas dos depoimentos que permitiram extrair os aspectos mais importantes, dentro do campo perceptivo, iluminado pela interrogação e que apontaram evidências da experiência vivida.

Cada entrevista foi analisada separadamente, com a numeração das unidades de significado, para então passar à fase subseqüente, de transformação da linguagem ingênua para a linguagem de pesquisadora. A terceira etapa de análise permitiu reunir todos os depoimentos para realizar o agrupamento das unidades de significado e as categorias convergentes, efetivando as convergências ou aspectos comuns.A quarta etapa somente foi alcançada após percorrer as anteriores, pois é este exercício dialético que permite a compreensão das descrições.

\section{EXPLICITANDO A COMPREENSÃO DO FENÔMENO}

Foram apreendidas 4 categorias convergentes na 
compreensão da pesquisadora e 11 unidades de significado. A seguir, são explicitadas as categorias convergentes com os depoimentos, seguidos do nome de sentimentos escolhidos pelos próprios sujeitos do estudo.

$\mathrm{Na}$ categoria convergente compreendendo a atitude humanística como mobilizadora das relações interpessoais em ambiente tecnológico hospitalar foi possível captar que os profissionais de saúde que trabalham em UTI convivem diariamente com situações que se articulam diretamente com seus sentimentos, emoções e defesas. Não é possível realizar as atividades técnicas, de alta precisão, se as emoções não estiverem lado a lado, acompanhando cada procedimento, cada momento no desenvolvimento do cuidado.

A atitude humanística é condição para a efetivação do cuidado, a qual não é conseguida com a vida, mas está no interior de cada ser humano que cuida, é cultivada no cotidiano das ações cuidativas. A atitude humanística não é imposta por meio de programas, normas ou rotinas estabelecidas pelas instituições, mas acontece e é vivenciada por todos os envolvidos. Essa conscientização da necessidade da atitude humanística para o cuidado da criança em ambiente tecnológico hospitalar é explicitada pelos sujeitos, como mobilizadora das relações interpessoais. O depoimento aponta:

Acho que atitude bumanistica para o cuidado tem que nascer com a pessoa, isso não bá como implantar, ou você tem ou você não tem. Não adianta você querer transformar um carrasco numa pessoa bumana, porque ele não vai ser, ou ele tem essa indole ou não tem. Isso é uma coisa que você pode até tentar lapidar, né? Pode até tentar melhorar isso. É individual de cada pessoa, isso vai da gênese de cada pessoa, entendeu (E2 -Espiritualidade).

A humanização em ambiente tecnológico hospitalar depende das pessoas envolvidas nas ações de cuidado. $\mathrm{O}$ esforço é de todos para que a humanização se estabeleça com suas diferentes interfaces como, conhecimento, comprometimento, consciência, doação, compartilhamento resultando no cuidado. O cuidado envolve a pessoa inteira com suas habilidades técnico-científicas e seus sentimentos, motivação, o desejo de aliar o humano e técnico, torna-se existência viva.

Eu acho que tem pessoas que sabem o que é [bumanização], mas não vão pôr em prática nunca, porque é da pessoa, o motivo não sei, mas que nunca vão por em prática (E8-Sinceridade).

Antes de tudo para a bumanização é preciso conbecimento, o cuidado engloba conhecimento, engloba a estrutura, amor. Você não conhece quem tá ali, mas, está precisando de cuidado. Com este conhecimento e este amor, você consegue ser maleável para fazer tanto o técnico e tanto a parte humana, né? Você consegue misturar as duas coisas (E1 - Amor).
As falas mostram que os profissionais têm um olhar voltado para a necessidade de envolvimento emocional nas suas relações de cuidado à criança em UTIP Cardíaca, muito mais que o desempenho técnico. Demonstram que aliar as dimensões expressivas às instrumentais auxilia na recuperação da criança.

Cuidado humanizado é estar perto dele, não chegar ali perto e olhar só equipamento e não tocar nele, não olhar para ele (E6Confianca).

Cuidar para mim é estar perto do paciente, ver o que é que está faltando, o que eu posso estar fazendo ali com ele. Com qual cuidado en vou deixar ele mais confortável, estar vendo um curativo, on se ele está sendo mudado de decúbito, se ele está recebendo as medicacoões certas. Como é que está o cuidado com ele (E6-Confiança).

O homem não apenas é e está no mundo, mas se relaciona com este, segundo seu modo de ser. O ser humano existe em co-naturalidade com os outros, portanto, o eu nunca está só. O encontro com o outro é um elemento essencial e integral nas relações recíprocas do ser e do mundo. "Os outros, não significa todo o resto dos demais, além de mim, dos quais o eu se isolaria", significa sempre um mundo compartilhado com outros. Nesse sentido, consideramos que, pela reflexão é possível captar o ser de cada um, ao compreender, captar as significações de cuidar em equipe e as nuances que se estabelecem nas relações humanas ${ }^{(12)}$.

$\mathrm{Na}$ categoria convergente, as relações interpessoais no ambiente tecnológico hospitalar envolvendo a equipe de saúde, os sujeitos revelaram que os sentimentos/ qualidades vivenciados pela equipe ao desenvolver as ações de cuidar estão intimamente relacionados ao modo de ser de cada profissional, com ênfase na humanização, nas relações interpessoais e na presença genuína e que estas relações têm forte impacto no cuidado direcionado à criança, neste ambiente tecnológico hospitalar.

As relações interpessoais envolvem a equipe de saúde na presença de sentimentos humanos, os quais têm repercussões nas ações de cuidado à criança; na comunicação como facilitadora para o conhecimento pessoal e interpessoal, e no poder que se institui entre os membros da equipe ao relacionarem-se. Muitos problemas nas relações interpessoais da equipe centramse na falta de comunicação adequada, em que não há perfeito entendimento do que está sendo comunicado, do resultado que espera, e como alcançar tal resultado.

E eu acho que muitas vezes fica de dificil compreensão o que a gente quer falar. Muitas vezes a gente briga, a gente fala por uma coisa que épara o bem do doente, mas não épessoal, o problema não épessoal, e falam a doutora tem problema com a enfermeira, com a auxiliar de enfermagem (E3 - Sensibilidade). 
Vocêfala uma vez, você fala duas vezes, três vežes e a pessoa não entende, você acaba desistindo. Eu agora estou tentando falar a quarta e a quinta vez. Tentando mostrar o ponto de vista e não ficar zangada, quando não faz̧em em relação ao que eu quero. Eu estou tentando me policiar mais (E3 - Sensibilidade).

Falar muito sobre alguma coisa não assegura em nada uma compreensão maior. Ao contrário, os discursos prolixos encobrem e emprestam ao que se compreendeu uma clareza aparente, ou seja, a incompreensão da trivialidade. O que escutamos em primeiro lugar, "são palavras incompreensíveis [...]. No escutar natural daquilo sobre o que se discorre, podemos, sem dúvida, escutar também o modo de dizer". Somente onde se dá a possibilidade existencial de discurso é que alguém pode ouvir. Quem não pode ouvir, e deve sentir, talvez possa muito bem, e justamente por isso, escutar. Discurso e escuta se fundam na compreensão ${ }^{(12)}$.

$\mathrm{Na}$ categoria convergente o sentido da presença da família nas relações interpessoais com a equipe de saúde foi possível compreender qual o sentido que a equipe de saúde explicita para a presença da família nas relações, neste ambiente. Os profissionais "com-vivem" com a família na UTIP Cardíaca e o preparo de ambos para se relacionarem reflete na recuperação da criança. Cuidar de uma criança é cuidar também da família, em todas as mobilizações que a envolvem, a relação com a família deve acontecer mediada pela atitude humanística.

Os participantes expressam que a falta de disponibilidade, devido à complexidade dos cuidados e prioridade que a equipe dá a alguns cuidados perante as necessidades de orientação e esclarecimentos da família, dificultam as relações. Mesmo com o entendimento sobre a participação da família no cuidado, a permanência da família, garantida por lei, e a existência de um programa na instituição que orienta a permanência dos pais em UTI, os relatos demonstram que ainda há resistência à presença da família no ambiente complexo.

Ver se a mãe está acompanhando ou não, ter uma relação com a familia é fundamental. Se a família tá acompanhando, você tem que ter uma relação além do paciente, tem que ter uma boa relação senão, não tem como (E1 - Amor).

No caso específico mais do que outras áreas, porque são crianças, então, eu tenho que tratar da criança, da mãe, do pai, do responsável pela criança, você tem que entender tudo isto e tem que dar um apoio psicológico muito grande pra família (E2 - Espiritualidade).

Tem umas mães que permanecem que a gente percebe que realmente ajudam na recuperação da criança, mas realmente são poucas, a maioria atrapalha. Atrapalha o nosso trabalho, às vezes a criança não está bem quando a mãe chega a criança fica mais agitada, mais nervosa, porque a mãe está muito ansiosa e passa aquilo para a criança. (E8-Sinceridade).

Dificulta bastante o trabalho. Eu acho que não é toda a familia que está preparada para ficar aqui dentro direto (E8-Sinceridade).

O tempo e a duração da internação afetam a estrutura e a organização familiar, levando a constantes ajustes no seu cotidiano. Os depoimentos reforçam que a equipe reconhece a busca da família por informações precisas e que a atenção cuidadosa pode minimizar o sofrimento vivenciado.

Como membro da equipe, eu com a família, procuro sempre explicar para a família o que é um pós-operatório, as complicacõoes. As vezes a criança apresenta alguma complicação e eu procuro explicar que aquilo é normal para aquela cirurgia, en procuro ser bem clara, assim, eu procuro explicar para deixar a familia o mais por dentro possivel (E8-Sinceridade).

$\mathrm{Na}$ complexidade do cuidar e do cuidado destacamse as vertentes técnica e tecnológica que contribuem para a materialização do cuidado na prática cotidiana e que, se não forem aplicadas de forma crítica, podem imprimir impessoalidade, distância e frieza, tornando o cuidado desumano e o cliente/família desubjetivado ${ }^{(13)}$.

A última categoria convergente analisada, a dinamicidade do cuidado permeando a conduta a ser tomada em ambiente tecnológico hospitalar expõe que são exigências, a perspicácia, eficiência profissional, conhecimentos, habilidades técnicas, mas principalmente o olhar atento de cuidador. A dinâmica do cuidar neste ambiente está fortemente baseada nas necessidades de cuidados complexos da criança que requer precisão técnica, está na compreensão da hostilidade do ambiente por suas próprias características, no impacto nas relações interpessoais nas ações de cuidar e na vontade de melhorar. Os profissionais percebem que para que, as relações sejam humanas neste local, é imprescindível aliar a capacitação e aperfeiçoamento técnico-científico à conscientização e aoaprimoramento da perspectiva humana e espiritual ao cuidar.

Importante salientar a preocupação com o estado geral da criança, de forma individualizada, com avaliação minuciosa, atenta e constante, no sentido de perceber o que pode ser modificado para melhorar as condições e bem-estar da criança. É o "estar-com" explicado por Paterson e Zderad como um tipo de fazer que, na realidade, implica na presença ativa do profissional. Em seu sentido mais amplo, o "estar-com" requer a fixação da atenção no paciente, estar atento a uma necessidade aqui e agora, na situação, é o comunicar-se disponível, respondendo adequadamente.

Eu cuido fazendo avaliação da criança da cabeça aos pés, né? Pra ver como é que tá. Em que situação que está em questão de complexidade, em questão de estado. Ai você faz um balanço geral para ver o que você pode efetuar em questão de complexidade e idade 
da criança. Ai você efetua conforme vai o dia-a-dia, conforme o plantão (E1 - Amor).

Ter um bom conhecimento do paciente, dele como um todo e, a gente ter clareza no estado clínico também. Poder estabelecer as prioridades. Acho que isso é o que facilita. E a passagem de plantão, que a gente possa ter uma visão linear de todos os pacientes (E7-Carinho).

Para a criança, tudo nesse ambiente é novidade. Eu tornaria mais aconchegante, facilitando a permanência da família com ele, fazendo alguma atividade que ele pudesse ficar confortável até ele melhorar (E6-Confiança).

Quando se mantêm uma estrutura de poder, a vida humana torna-se fragilizada e a subjetividade já não tem valor $^{(5)}$.

Ao aprisionar o cuidar em normas, rotinas e técnicas, estas alienam o cuidado de sua existência criadora e reveladora. Assim, hão de ser empregadas respeitandose o direito à criatividade, o direito à apreciação e o conhecimento dos seres envolvidos tornando-as flexíveis e permeadas de atitude humana ${ }^{(14)}$.

Os entrevistados exteriorizaram a compreensão da hostilidade do ambiente por suas próprias características e o impacto nas ações de cuidar. A equipe multiprofissional necessita conhecer como responder, positivamente, aos estímulos estressores, lembrar ao cuidar, que além das reações que se desencadeiam na perspectiva de um ser humano, a criança apresenta alterações comportamentais, emocionais e físicas específicas a sua compreensão, de acordo com a etapa de crescimento e desenvolvimento. Uma equipe de trabalho que permanece estável e qualificada, além de sustentar o processo de cuidar, cria possibilidades efetivas de garantia da qualidade dos serviços ofertados em uma UTI.

O que dificulta no cuidado em UTI, eu acho que primeiro, o próprio ambiente que é um ambiente extremamente estressante (E3 - Sensibilidade).

O estímulo luminoso, o estímulo doloroso, a sensação de estar sozinho, a falta de comunicação, a dor, a ansiedade, o vazio, a permanência no leito sem poder se levantar, enfim os conbecimentos dos estimulos externos. Eu acho que tudo isso é um problema. São problemas que estressam a criança (E7-Carinho).

Para atingir a plenitude, estamos caminhando, mas, eu diria que hoje a gente tem muito a avançar neste campo de conbecimento de quão intenso isto épara o paciente (E7-Carinho).

Com a equipe de saúde da UTIP Cardíaca foram vivenciados momentos permeados pelos conceitos humanísticos da enfermagem fenomenológica e os discursos apreendidos mostraram que os seres humanos que ali atuam preocupam-se com o "com-viver" neste ambiente repleto de tecnologia e como esta convivência ecoa nas formas de cuidar da criança.

\section{CONSIDERAÇÕES FINAIS}

A compreensão deste fenômeno à luz da Teoria Humanística de Paterson e Zderad revela-se como ele se mostra, se manifesta e se apresenta, pois as relações interpessoais acontecem de forma intersubjetiva, equipecriança-família, neste ambiente de cuidados complexos.

A contribuição deste estudo para a enfermagem é a demonstração que o cuidado, quando permeado pelos conceitos da enfermagem humanística, como relação dialógica, presença, encontro genuíno e transação intersubjetiva respeita as relações interpessoais estabelecidas no encontro dos profissionais com a criança e família; auxilia no equilíbrio do cuidado, aliando a técnica e a dimensão humana, e traduz-se em um cuidado solidário que ajuda, respeita, vincula, acolhe e enobrece as qualidades humanas.

Este estudo não esgota o tema abordado, porque as maneiras de ver e sentir um fenômeno são dinâmicas e relacionadas ao contexto em que se situa. É possível, com novos estudos e pesquisas, progredir no objetivo de refinar outras compreensões de como a equipe de saúde estabelece suas relações interpessoais ao cuidar, em distintos ambientes tecnológicos hospitalares.

Os resultados obtidos neste estudo devem ser considerados na formação de novos profissionais que escolherem os ambientes tecnológicos hospitalares para atuação, e também no aprimoramento dos profissionais já atuantes.

É fundamental que a equipe de saúde que atua em um ambiente eminentemente tecnológico não prescinda ao cuidado humano, por mais eficientes e modernos que sejam os equipamentos. Tornar a tecnologia e a atitude humanística, verdadeiros aliados, é a forma mais apropriada de cuidar, a qual deve ser percebida, compreendida, assumida e implementada pela equipe neste ambiente.

Foi possível apreender nas falas, que os profissionais de saúde estabelecem relações interpessoais ao cuidar em ambiente tecnológico hospitalar, e percebem que, para cuidar, é necessário muito mais do que a realização de atividades técnicas, vinculando a presença de sentimentos humanos nas ações de cuidar. A enfermagem caracteriza-se por ter, como princípio, o critério do humanismo, e é possível estender essa forma de agir aos demais profissionais da área de saúde que atuam de forma compartilhada em ambiente complexo hospitalar, pois são profissionais que se compadecem pela dor e sofrimento da criança, que compreendem a importância de suas ações, que definem claramente os seus limites de atuação profissional.

Diante de todas as exigências profissionais, a equipe "com-vive" com o ambiente estressante, exaustivo, solicitador, exigente. Assim, o ambiente de UTIP Cardíaca exige profissionais tecnicamente competentes, 
equilibrados emocionalmente, e que saibam administrar o ambiente conturbado e exigente de UTI pela motivação, estímulo e comunicação eficaz.

O mundo da UTIP Cardíaca não pode ser concebido sem a presença dos profissionais de saúde, crianças, familiares, e que estes homens não podem ser compreendidos independentemente desse mundo. $\mathrm{O}$ mundo, o ambiente, onde estão inseridos os homens é concebido, porém os homens, os profissionais de saúde, são compreendidos a partir desse mundo.

O intersubjetivo é uma esfera em que o sujeito se defronta efetivamente com o outro, e nesse confronto,

\section{REFERÊNCIAS}

1. Bettinelli LA. A solidariedade no cuidado: dimensão e sentido da vida. Florianópolis: UFSC/PEN; 2002. ( Teses em Enfermagem; 41).

2. Cunha PJ. As relações interpessoais nas ações de cuidar em ambiente tecnológico hospitalar (dissertação mestrado). Curitiba: Universidade Federal do Paraná; 2007.

3. Vila VSC, Rossi LA. O significado cultural do cuidado humanizado em unidade de terapia intensiva: muito falado e pouco vivido. Rev Latinoam Enferm. 2002; 10(2): 137-44.

4. Pessini L. Humanização da dor e do sofrimento humanos na área da saúde. In: Pessini L, Bertachini L, organizadores. Humanização e cuidados paliativos. São Paulo: Centro Universitário São Camilo / Edições Loyola; 2004.

5. Melo F. Quem me roubou de mim? O seqüestro da subjetividade e o desafio de ser pessoa. São Paulo: Editora Canção Nova; 2008.

6. Mandú ENT. Intersubjetividade na qualificação do cuidado em saúde. Rev Latinoam Enferm. 2004; 12(4):665-75.

7. Paterson JG, Zderad LT. Humanistic nursing. 2a ed. New que não é mera experiência psicológica, há uma realidade em que os dois sujeitos convivem. O eu é uma pessoa, o tu é uma pessoa. As pessoas estão envolvidas pela comum realidade, pela realidade de ser-com, o que fundamenta sua existência.

O cuidado em um ambiente tecnológico como UTIP Cardíaca precisa ser permeado de valores e sentimentos humanos que visem o bem-estar e o estar melhor da equipe/ criança/ família, colocando em cena peculiaridades do universo afetivo, cultural e social dos sujeitos envolvidos, pela presença genuína e autêntica estabelecida na atitude humanística ao cuidar.

York (NY): National League for Nursing; 1979.

8. Rolim KMC, Pagliuca LMF, Cardoso MVLML. Análise da teoria humanística e a relação interpessoal do enfermeiro no cuidado ao recém-nascido. Rev Latinoam Enferm. 2005; 13(3):432-40.

9. Ayres JRCM. Cuidado: tecnologia ou sabedoria prática? Interface Comum Saude Educ. 2000; 4(6):117-20.

10. Araújo LZS. Aspectos éticos da pesquisa científica. Pesqui Odontol Bras. 2003; 17(Supl 1): 57-63.

11. Giorgi A. Phenomenological and psychological research. Pittsburg: Duquesne University Press; 1985.

12. Heidegger M. Ser e tempo. 3a ed. Petrópolis: Vozes; 1989. Pt. 1.

13. Ferreira MA. As correntes teóricas e práticas das dimensões do cuidar na infância: abordagem introdutória ao tema. Esc Anna Nery Rev Enferm. 2002; 6(Supl 1): 75-8.

14. Nogueira VMR, Pires DEP. Direito à saúde: um convite à refexão. Cad Saude Publica $=$ Rep Public Health. 2004; 20(3),753-60. 